\title{
Climate Change In Colombia: Trends And Perspective to Achieve Sustainable Development
}

\author{
Clara Inés Pardo Martínez
}

\begin{abstract}
Colombia is recognized as a country that has at high-risk and vulnerability from climate change impacts, which can affect diverse human settlements, development and economic activities. Hence, in rural areas the main challenges are the means of living and food production, whereas, in urban contexts climate change should decrease heath conditions and quality of life. This research seeks to analyse and evaluate trends and perspectives of climate change in Colombia in the last decade using qualitative and quantitative methods that allow to determine whether in this country climate governance has contributed to the mitigation and adaptation to climate change, especially in vulnerable areas that are more likely to poverty. Results indicate that in the up coming 15 years in the most areas of the country the temperature will increase $1{ }^{\circ} \mathrm{C}$ which should undermine development especially in poor and rural areas. Despite quite a climate governance, it is necessary to strength its application and to raise awareness about importance to promote sustainable development from housing to the productive sector to achieve mitigation and adaptation to decrease and control risks by new weather conditions. All findings of this study are important for policy makers and local government to improve the mechanisms to adapt and mitigate climate change in Colombia where climate change should increase poverty and inequality.
\end{abstract}

Keywords: Climate change, perception, qualitative and quantitative analysis, Colombia

\section{Introduction}

In recent decades, the increase of anthropogenic greenhouse gas (GHG) emissions has transformed the composition of the atmosphere and changed the global climate system, including the amount and pattern of precipitation around the world (UNDP, 2004). GHG emissions have increased by an average of $2.2 \%$ per year during the period of 2000 to 2010, and in the last year, anthropogenic GHG emissions reached $49 \pm 4.5 \mathrm{GtCO}$-eq; this increase in emissions has been related to changes in snow cover, ice extent, sea level and precipitation (IPCC, 2014).

These facts indicate that climate change is occurring, and it is important for policy makers, researchers, decision-makers and citizens to generate and deploy new and cleaner technologies and take actions and measures that involve some level of citizen participation; the instruments of policy mandates to active behavioral change should be adopted (Dietz and Stern, 2008, Shwom et al., 2010).

In this context, it is important to analysis trends and perceptions of population on climate change to determine different approaches on reality of climate change in Colombia that it is a country particularly vulnerable to climate change, given that its population has been established in areas that are prone to flooding and in unstable lands 
of the high sierras. Moreover, this country shows a high recurrence and amount of disasters related to climatic conditions (UNDP, 2010). From this context, the objective of this research is to gather and analyze the perceptions of the Colombian population regarding climate change and main trends.

This paper is divided in five sections beginning with the present introduction, second the main features of climate change in Colombia, third methods, fourth the main results and discussion and finally conclusions.

\section{Climate Change in Colombia}

Colombia is one of the countries that is most vulnerable to climate change because coastal and mountain ecosystems directly benefit $80 \%$ of the population. In the few last years, climate change has been wreaking havoc in different regions, generating flooding, landslides, and changes in water provisions, impacting human health and more; hence, it is critical to protect this country against climate impacts.

In the last few decades, this country has been working on different policies related to climate change (IDEAM et al., 2015a): In 1994, it promulgated law 164, which approved the United Nations Framework Convention on Climate Change (UNFCCC). In 2000, it promulgated law 629, which ratified the Kyoto Protocol and formulated the National Strategy for the Implementation of the Clean Development Mechanism (CDM). In 2001, it made the first national communication regarding climate change and the first national inventory of GHG emissions (1990 and 1994). In 2002, it generated the first policy guidelines on climate change and established the National Office of Climate Change. In 2005 , it established the mitigation group of climate change. In 2009, it made a national inventory of GHG emissions (2000 and 2004). In 2010, it made a second national communication regarding climate change and created an adaptation fund. In 2013, it formulated the roadmap for climate change adaptation programs and plans. In 2015, it formulated the proposal of the national climate change policy. These facts demonstrated that the country has made large strides in improving the resilience of its citizens to the climatic changes that threaten their water sources and livelihoods through different strategies and policy instruments.

Moreover, this country has developed a Colombian Strategy of Low Carbon Development that included the following issues: i. An analytical phase to identify and formulate mitigation measured for productive sectors; ii. the development of action plans for mitigation and studies of the co-benefits of mitigation measures; iii. the implementation of a measuring system of mitigation actions; iv. capacity-building; and v. communication strategies. This strategy has allowed for the development of eight plans of action for the main productive sectors to improve sustainable development and decrease GHG emissions.

The last national inventory of GHG emissions for the year 2012 (IDEAM et al., 2015b) indicated that Colombia generated $178258 \mathrm{Gg}$ of CO2 equivalents, for which energy, agriculture, forestry, and other land use accounted for $87 \%$ of the GHG emissions (see Figure 1). 

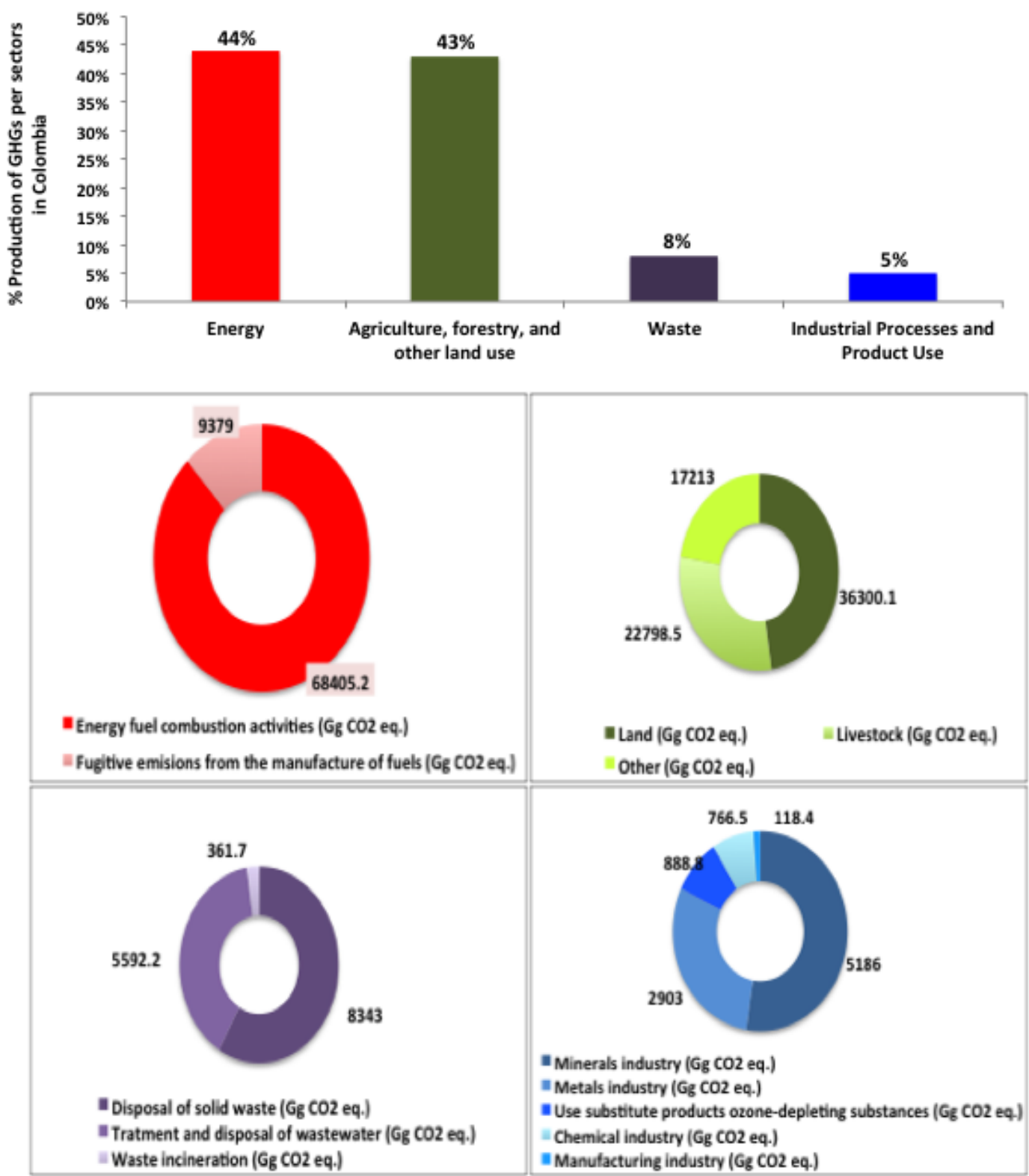

Figure 1. GHG emissions in Colombia in percentage and $\mathrm{Gg}$ of $\mathrm{CO}_{2}$ equivalent (2012)

\section{Methods}

A nationally representative quota sample of the Colombian population aged 18 years and older was interviewed face-to-face in their own homes by OCyT-SEI between 1 April and 15 May 2016. Sampling was random and stratified, which allowed for a representative sample, and the technique used for the sample design was principal 
component analysis (PCA), an regions were assigned using the technique of optimal X allocation.

The questionnaire was designed taking into account the five categories: sociodemographic data, values and positions on climate change, information and communication, governance and behavior related to this issue.

\section{Results and Analysis}

This section shows the main results of this study on climate change that was calculated with statistical techniques of high reliability. Results indicates different approaches on perceptions and ideas of climate change in Colombia taking into account the socio-demographic characteristics. In general, Colombian population if it considers that climate change is happening and it is perceived through changes in temperature and rainfall, it is caused by human activities and in Colombia the actions in relation to climate change are limited.

A national representative quota sample of 1130 people aged 18 years and older was interviewed face-to-face in their own homes and represents 11754627 of Colombian citizens. The survey guarantees to gender-impartial composition the following manner: women $51.28 \%$ and men $48.72 \%$. The majority of respondents $(76.18 \%)$ had primary and secondary education.

Questions on beliefs and knowledge regarding climate change show the most important representations and their dynamics according to the respondents to be recognized. The majority of respondents believe that climate change is real $(98.33 \%)$ and that human activity is the principal factor contributing to it $(90.34 \%)$. On average, $56.77 \%$ consider that in their regions, the annual average temperature is warmer, and $36.56 \%$ consider that it has been variable over the last five years. The amount of rain has decreased according to $54.02 \%$ of respondents, and $31.22 \%$ have stated that rainfall has been variable in the last five years. Moreover, respondents relate to climate change with the following words: temperature, changes, droughts, and rainfall, among others (see Figure 2).

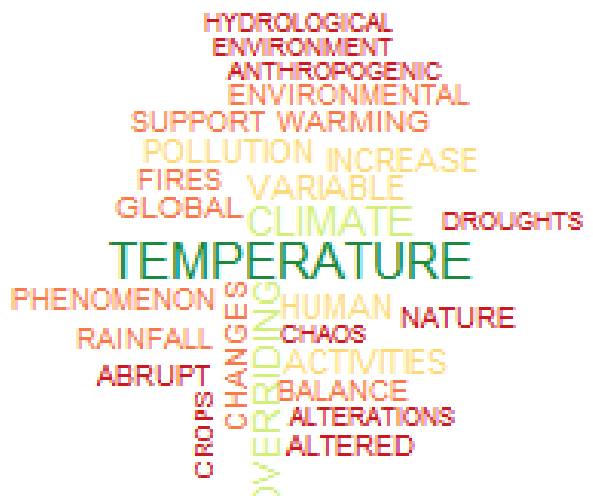

Figure 2. Words related to climate change in Colombia 
The survey indicated that the main causes of climate change for respondents (see figure 3) are deforestation (30.33\%), inadequate solid waste management $(23.74 \%)$ and air pollution generated by industries $(22.02 \%)$. In general, the trends by region, age, area and education level are similar considering the deforestation as the main cause of climate change, which concurs to data of IDEAM (2014) that demonstrated a gradual decline of Colombian natural forest from an area of 56.4\% in 1990 to $51.7 \%$ in 2014.

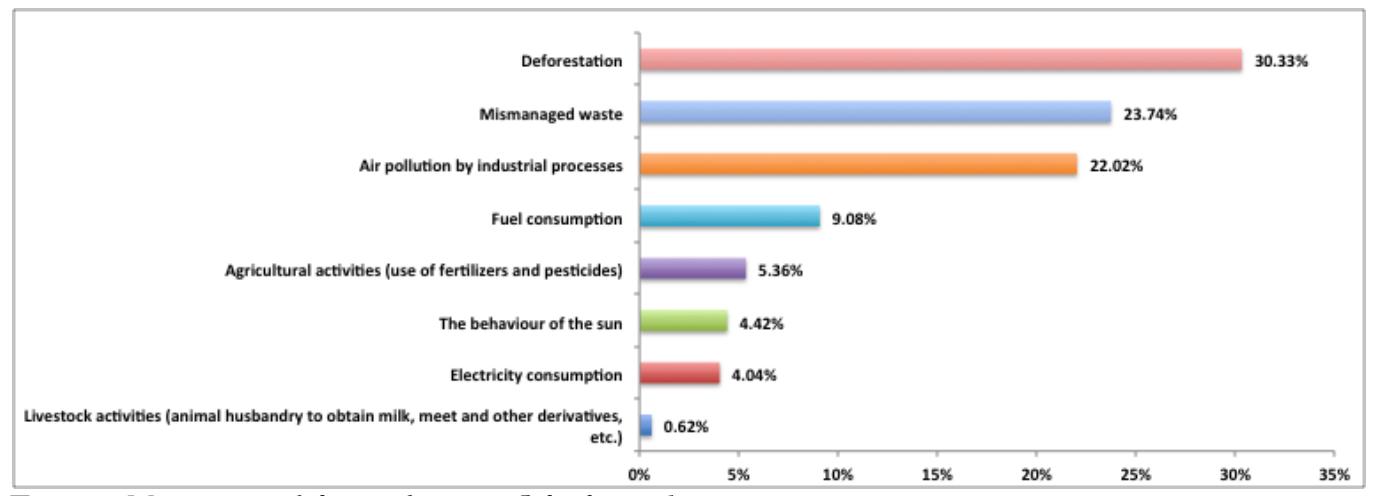

Figure 5. Main causes of climate change in Colombia and regions

$25 \%$ of respondents consider that they are very well informed or informed, whereas $62.19 \%$ consider that they are not sufficiently well informed on climate change. In the regions (see Figure 6).

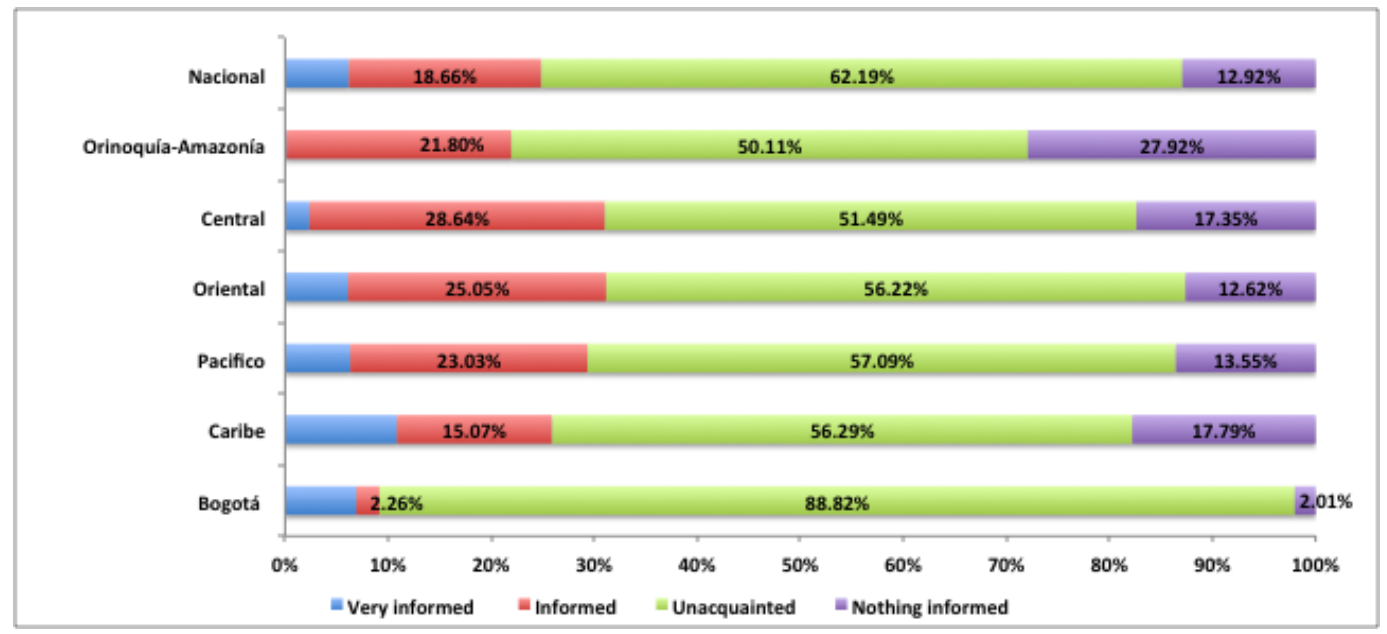

Figure 6. Level of information on climate change in Colombia and regions

The main media platform to inform them of climate change is television, followed by the Internet. The programs that are recognized to provide information about climate are mainly the Discovery Channel, Week radio_No Numeral, RCN newscast, etc. (See Figure 7). 


\section{THEWEEK OF SUSTAINABLE DEVELOPMENT YOUTU⿴囗十 RTNEWSCAST \\ NATIONALGEOGRAPHIC \\ ECOLOGYNEWSPAPER}

IDFAMCOIP

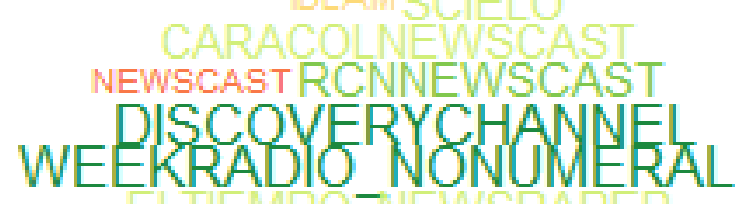

\section{GEOPLANET}

NATIONALNEWSCAST

WEBPAGE OF CORPOAMAZONIA

WEBPAGE_OF_THE_MINISTRY_OF_ENVIRONMENT

Figure 7. Programs recognized to inform the public about climate change

To analyze the government actions or programs regarding climate, the survey included three questions in which investments for climate change, education campaigns and the formulation of policies and instruments are the actions executed by the Colombian government. However, over $40 \%$ of respondents consider that these actions for climate change are not executed in Colombia (see Figure 8).

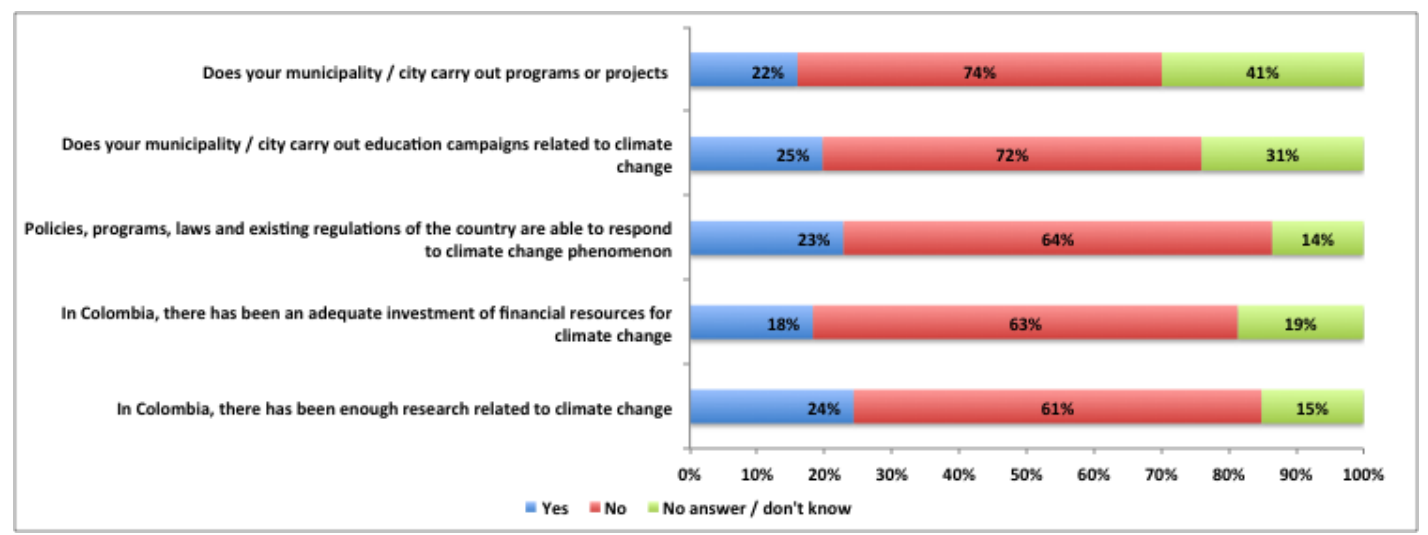

Figure 8. Perceptions related to institutional activities on climate change in Colombia

Less than $20 \%$ of respondents have used forums for public participation on climate change; alternatively, more have used the following: environmental municipal councils, committees of citizen participation and community action councils.

The government offices most recognized to conduct actions in response to climate change are the Ministry of the Environment, the National Unit for Disaster Risk Management, and IDEAM. However, for every entity, less than $20 \%$ of respondents identified these entities as promoting action to combat climate change. 
The main activities identified by the respondents for adaptation to climate change are the following: reducing water consumption, changing of the manner of dress, and changes in infrastructure (see Figure 9).

Moreover, in regards to actions and practices for adaptation to climate change, $83 \%$ of respondents have not applied any practice or action, and 75\% have applied new actions for local water management.

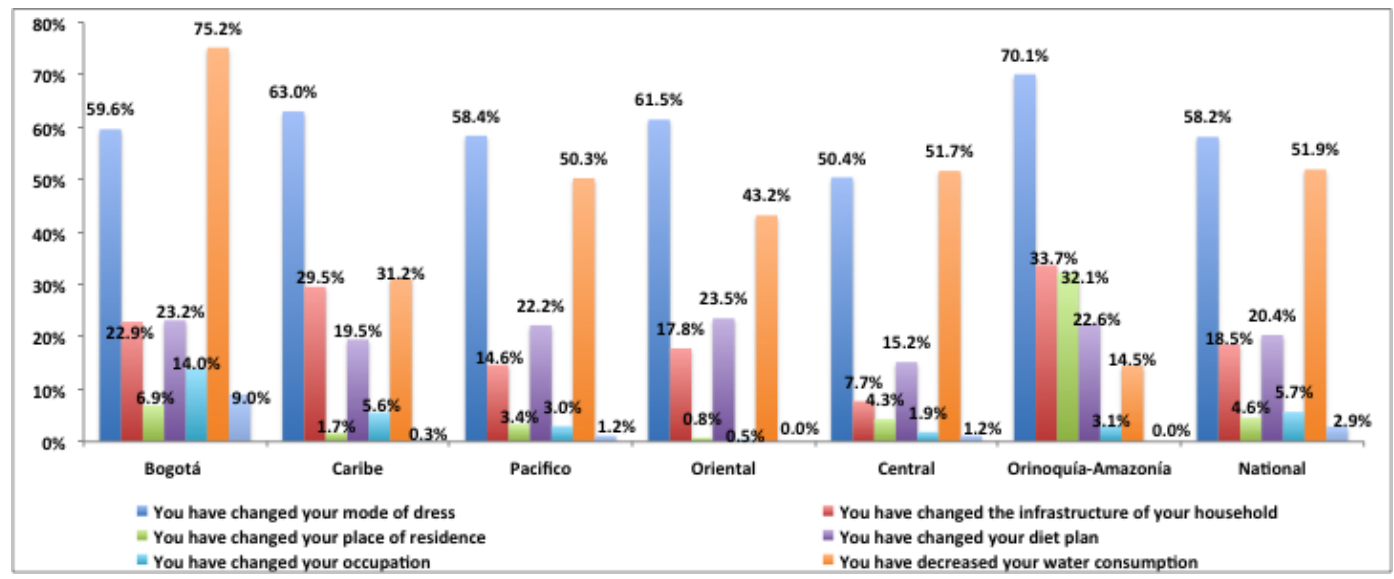

Figure 9. Activities for adaptation to climate change according to respondent answers of the survey in Colombia and regions.

The findings of this study indicate that the Colombian people have developed different concepts and knowledge on climate change, for which it is important to design and apply new strategies to empower the population on the importance and actions for adaptation or mitigation of climate change. Additionally, the government should strengthen climate change governance, especially in the regions that are most affected by this situation.

\section{Conclusions}

The results of this study have demonstrated that the majority of the Colombians interviewed believe climate change to be an important issue. They note that it is real and that human activity is a contributing factor. The researchers have identified that the Colombian population has perceived changes in temperature and rainfall over the last five years, and these changes have generated threats to their habitat in the form of droughts, rising food prices, forest fires, among others. The main media platforms to inform the public on climate change are television and the Internet.

On the whole, this research reveals that climate change governance has gaps because over $60 \%$ of respondents consider that the country does not execute or apply actions to combat climate change, and less than 10\% have used forums for public participation on climate change. Moreover, the majority of Colombians have not applied any practice or action to adapt to climate change. 
It is important to design strategies and instruments in which citizens can become more involved in actions to prevent, mitigate and adapt to climate change and in which government and the media also play significance roles. Identifying current perceptions is not sufficient; it is also necessary to identify and analyze climate change from an integral perspective that guarantees effective migration strategies, such as the development of a low carbon economy.

\section{References}

Dietz, T. and Stern, PC., Public Participation in Environmental Assessment and Decision Making. Washington, DC: National Academies Press; 2008.

IDEAM, PNUD, MADS, DNP and Chancellery, First Biennial Report of update Colombia for UNFCCC, Bogotá, 2015a.

IDEAM, PNUD, MADS, DNP and Chancellery, National Inventory of Green House Gas Emissions in Colombia, Bogotá, 2015b.

IDEAM, Sub-direction of Ecosystems and Environmental Information. Forest Group 2014. Project: Monitor System of Forest and Carbon. Bogotá, D. C., Colombia, 2014.

Intergovernmental Panel on Climate Change (IPCC), Climate Change 2014, https://www.ipcc.ch/pdf/assessment-report/ar5/syr/AR5_SYR_FINAL_SPM.pdf, 2014.

Shwom, R., Bidwell, D., Dan, A., Dietz, T., Understanding US public support for domestic climate change policies, Global Environmental Change, Vol. 20, pp 472-482, 2010.

United Nations Development Programme (UNDP), World Energy Assessment: Overview 2004 Update. UNDP, World Energy Council, New York, 2004.

United Nations Development Programme (UNDP), Mainstreaming Climate Change in Colombia. Screening for risks and opportunity, http://www.undp.org/content/dam/ aplaws/publication/en/publications/environment-energy/www-ee-library/climate-change

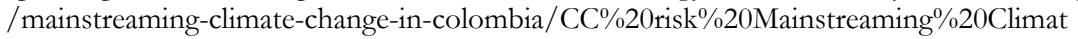
e\%20Change $\% 20$ in $\% 20$ Colombia-EN.pdf, 2010. 